\title{
Postgastrectomy polyneuropathy with thiamine deficiency
}

\begin{abstract}
H Koike, K Misu, N Hattori, S Ito, M Ichimura, H Ito, M Hirayama, M Nagamatsu,
\end{abstract} I Sasaki, G Sobue

\begin{abstract}
Objective-Polyneuropathy has been reported after gastrectomy performed to treat various lesions. Although thiamine deficiency is a possible cause of this neuropathy, the pathogenesis still remains to be clarified. Seventeen patients with peripheral neuropathy with thiamine deficiency after gastrectomy are described.

Methods-Seventeen patients with polyneuropathy after gastrectomy accompanied by thiamine deficiency were selected. Patients were restricted to those with total or subtotal gastric resection to treat ulcer or neoplasm. Patients who had undergone operations to treat morbid obesity were excluded.

Results-Intervals between the operation and onset of neuropathy varied from 2 months to 39 years. Most patients did not seem malnourished. Serum concentrations of $B$ vitamins other than thiamine were nearly normal. Symmetric motorsensory polyneuropathy, predominantly involving the lower limbs, had progressed over intervals varying from 3 days to 8 years. Relative degrees of motor and sensory impairment also varied extensively. Some cases that progressed rapidly mimicked Guillain-Barré syndrome. Electrophysiological and pathological findings were those of axonal neuropathy. Substantial functional recovery from polyneuropathy was seen in most patients by 3 to 6 months after initiating thiamine supplementation. Motor recovery was better than sensory recovery.

Conclusions-Various symptoms were seen in patients with postgastrectomy neuropathy. Thiamine deficiency should be considered in the differential diagnosis of motor-sensory polyneuropathy after gastrectomy.

(尹 Neurol Neurosurg Psychiatry 2001;71:357-362)
\end{abstract}

Keywords: neuropathy; beriberi; gastrectomy; thiamine

Deficiency of thiamine (vitamin B1) causes peripheral neuropathy and heart failure, designated as beriberi. Wernicke-Korsakoff syndrome may also occur. ${ }^{1}$ Beriberi was an endemic disorder among Asians for whom milled white rice was the staple diet in the late 19 th century. ${ }^{2}$ The number of patients with beriberi decreased markedly after discovery of the vitamin, ${ }^{3}$ and public education on the need for a balanced diet. Since then, beriberi has been considered to be rare and forgotten by many physicians, especially those in developed countries. However, recent reports suggest that neuropathy associated with thiamine deficiency is not uncommon among patients with various background factors including chronic alcoholism $^{4}$ and prolonged parenteral nutrition. ${ }^{5}$

Neuropathy and Wernicke's encephalopathy have been reported to occur after gastric restriction surgery for morbid obesity. ${ }^{6-8}$ After such operations, patients often experience protracted nausea and vomiting, leading to malnutrition and extensive weight loss. Recently, Wernicke's encephalopathy was reported to occur after gastrectomy for cancer, ${ }^{9-12}$ suggesting that manifestations of thiamine deficiency, including beriberi, can occur in patients after gastrectomy as well. Previously, in the early 1970s, Banerji et $a l^{13}$ and Hoffman et $a l^{14}$ raised the possibility that neuropathy can occur after partial gastrectomy for peptic ulcer. The pathogenesis of these neuropathies has not yet been defined. Malnutrition associated with malabsorption or decreased oral intake was suspected, but some patients showed no signs of malnutrition - for example, hypoalbuminaemia or steatorrhoea. ${ }^{13}{ }^{14}$ As previous reports of postgastrectomy neuropathy did not focus specifically on thiamine deficiency, the relation of this deficiency to this neurological complication has not been well understood. In the present report we examined and characterised 17 patients with polyneuropathy and thiamine deficiency after gastrectomy.

\section{Patients and methods}

Patients studied consisted of 12 men and five women ranging in age from 42 to 69 years (mean (SD) 57.4 (9.4) years, table 1). They were referred to Nagoya University Hospital and its affiliated institutions between 1990 and 1999. Inclusion criteria for this study required polyneuropathy, thiamine deficiency, and a history of total or subtotal gastrectomy preformed to treat ulcer or neoplasm. Polyneuropathy was defined on clinical grounds of symmetric impairment of both muscle strength and sensation, and hyporeflexia or areflexia of the limbs. It was confirmed by sural nerve biopsies or nerve conduction studies. Patients who had undergone gastric restriction surgery for morbid obesity were excluded. Patients underwent general physical and neurological examinations, routine blood and urine studies, blood thiamine determinations, CSF analyses, cranial MRI and CT, EMG, nerve conduction studies, and sural nerve biopsy. Concentrations of total thiamine were determined in whole 


\begin{tabular}{|c|c|c|c|c|c|c|c|c|c|c|c|c|c|c|c|}
\hline \multirow[b]{2}{*}{ Patient } & \multirow[b]{2}{*}{ Age } & \multirow[b]{2}{*}{ Sex } & \multirow[b]{2}{*}{ Progression } & \multirow[b]{2}{*}{$\begin{array}{l}\text { Initial } \\
\text { symptom }\end{array}$} & \multicolumn{2}{|c|}{ Motor symptoms } & \multicolumn{2}{|c|}{ Sensory symptoms } & \multirow[b]{2}{*}{$\begin{array}{l}\text { Autonomic } \\
\text { symptoms }\end{array}$} & \multirow[b]{2}{*}{$\begin{array}{l}\text { Cranial } \\
\text { nerve } \\
\text { involvement }\end{array}$} & \multicolumn{4}{|c|}{ Associated symptoms } & \multirow[b]{2}{*}{$\begin{array}{l}\text { Thiamine } \\
\text { concentration } \\
\text { (ng/ml) }\end{array}$} \\
\hline & & & & & $\begin{array}{l}\text { Muscle } \\
\text { strength }\end{array}$ & $\begin{array}{l}\text { Muscle } \\
\text { atrophy }\end{array}$ & $\begin{array}{l}\text { Touch/ } \\
\text { pain }\end{array}$ & $\begin{array}{l}\text { Vibration/ } \\
\text { joint } \\
\text { sense }\end{array}$ & & & WWS & Cardiomegaly & $\begin{array}{l}\text { Oedema } \\
\text { of the } \\
\text { legs }\end{array}$ & Myalgia & \\
\hline 1 & 46 & M & 1 month & M & $3+$ & + & $3+$ & $3+$ & + & - & + & + & + & - & 15 \\
\hline 2 & 42 & M & 2 months & $\mathrm{S}$ & $2+$ & - & $2+$ & $2+$ & - & - & - & - & - & - & 5 \\
\hline 3 & 69 & $M$ & $4 \mathrm{y}$ & $M$ & $2+$ & + & $2+$ & $3+$ & - & - & - & - & + & - & 14 \\
\hline 4 & 50 & $\mathrm{~F}$ & 1 month & M & $3+$ & - & $2+$ & $3+$ & + & + & - & - & - & + & 15 \\
\hline 5 & 47 & M & $1 \mathrm{y}$ & $\mathrm{S}$ & $2+$ & + & $1+$ & $1+$ & - & - & - & - & - & - & 15 \\
\hline 6 & 54 & $\mathrm{~F}$ & 1 month & M & $3+$ & + & $3+$ & $3+$ & + & - & - & - & + & - & 12 \\
\hline 7 & 52 & $\mathrm{~F}$ & 3 weeks & M & $3+$ & + & $2+$ & $2+$ & + & - & + & + & + & - & 8 \\
\hline 8 & 68 & M & 2 months & S & $3+$ & + & $3+$ & $3+$ & + & + & + & - & - & - & 8 \\
\hline 9 & 65 & $M$ & $8 \mathrm{y}$ & M & $2+$ & + & $3+$ & $3+$ & - & - & - & + & + & + & 10 \\
\hline 10 & 66 & $\mathrm{~F}$ & 1 month & $M$ & $3+$ & - & $2+$ & $2+$ & - & - & - & - & - & - & 15 \\
\hline 11 & 61 & M & 3 weeks & M & $3+$ & - & $3+$ & $3+$ & - & - & - & - & - & - & 15 \\
\hline 12 & 66 & $\mathrm{~F}$ & 1 month & $\mathrm{S}$ & - & - & $2+$ & $1+$ & + & - & - & + & + & - & 6 \\
\hline 13 & 68 & M & 3 days & M & $3+$ & + & $1+$ & $2+$ & - & - & + & - & - & - & 5 \\
\hline 14 & 48 & M & 1 month & $M$ & $3+$ & + & $3+$ & $3+$ & - & + & - & - & + & - & 12 \\
\hline 15 & 67 & M & 1 month & S & $3+$ & + & $2+$ & $1+$ & - & - & - & + & + & - & 17 \\
\hline 16 & 48 & M & 3 months & $\mathrm{S}$ & $3+$ & - & $1+$ & $3+$ & + & + & - & + & + & + & 10 \\
\hline 17 & 58 & $M$ & 6 months & $M$ & $2+$ & + & $2+$ & $2+$ & - & - & - & - & + & + & 9 \\
\hline
\end{tabular}

WKS=Wernicke-Korsakoff syndrome; $M=$ muscle weakness; $S=$ sensory disturbance; -=absent; +=present; $1+=$ mild; 2+=moderate; $3+=$ severe

Normal thiamine concentration (mean \pm 2 SD for normal control) is $20-50 \mathrm{ng} / \mathrm{ml}$.

blood using high performance liquid chromatography (HPLC). Activity of transketolase in erythrocytes was analyzed spectrophotometrically. In addition to thiamine, plasma concentrations of vitamin B2, B6, B12, folate, and vitamin $\mathrm{E}$ were determined before vitamin administration.

Diagnosis of thiamine deficiency in this study required a low total thiamine concentration in whole blood $(<20 \mathrm{ng} / \mathrm{ml}$; representing the mean-2 SD for normal control subjects) and improvement of clinical symptoms in response to thiamine administration. Normal values for whole blood concentration of total thiamine were established from a study of 100 normal volunteers (mean age (SD), 29.7 (5.0) years; men : women, $50: 50$ ). Patients who did not show decreased erythrocyte transketolase activity were also excluded ( $<23.8$ units/l, the mean-2 SD for normal controls) according to data from a previous report. ${ }^{15}$

A detailed history was obtained from each patient, or family members, or both about lifestyle, occupation, diet, and daily consumption of alcohol. Those with a daily consumption of alcohol were excluded from the series. Four subjects not excluded had occasional intake of alcohol in small amounts not exceeding 20 $\mathrm{g} /$ occasion. Most patients included in this study were careful to maintain a balanced diet after surgery, but four patients $(6,9,11$, and 14) showed slight hypoproteinaemia. Patients with chronic inflammatory demyelinating polyneuropathy, Guillain-Barré syndrome, critical illness neuropathy, mitochondrial encephalopathy, and other neuropathies with an aetiological background other than thiamine deficiency were excluded from the series.

Motor and sensory conduction studies were performed for the median, ulnar, tibial, and sural nerves in all patients during the acute phase of illness using a standard method. ${ }^{16}{ }^{17}$

Sural nerve biopsies were performed in 12 patients as described previously, ${ }^{18-20}$ ordinarily before administration of thiamine. Specimens were divided into two portions. The first portion was fixed in $2.5 \%$ glutaraldehyde in $0.125 \mathrm{M}$ cacodylate buffer ( $\mathrm{pH} 7.4$ ) and then embedded in epoxy resin. The density of myelinated fibres was assessed in toluidine blue stained semithin sections using a computer assisted image analyzer (Luzex FS; Nikon, Tokyo, Japan), and densities of small and large myelinated fibres were calculated as described previously. ${ }^{19-21}$ The extent of subperineurial oedema was assessed as a ratio of increased subperineurial space due to oedema to the total endoneurial area using the same imaging system. ${ }^{22}$ To assess the density of unmyelinated fibres, electron microscopic photographs at a magnification of $\times 4000$ were taken in a random fashion to cover the ultrathin transverse section, ${ }^{19-21}$ and the density was estimated from the photomicrographs. A portion was processed for a teased fibre study in which at least 100 single fibres were isolated and assessed pathologically according to criteria described previously. ${ }^{21} 2324$

Patients' functional status was assessed according to a modified Rankin score ${ }^{25}$ for up to 2 years: 0 asymptomatic; 1 non-disabling symptoms not interfering with lifestyle; 2 minor disability from symptoms leading to some restriction of lifestyle but not interfering with the patients' capacity to look after themselves; 3 moderate disability from symptoms significantly interfering with lifestyle or preventing a totally independent existence; 4 moderately severe disability from symptoms clearly precluding independent existence, al though not requiring 24 hour attention from a caregiver; and 5 severe disability and total dependence, requiring constant attention day and night.

Statistical analyses were performed using the Mann-Whitney $U$ test or Spearman's rank correlation analysis. $\mathrm{p}$ Values $<0.05$ were considered significant.

\section{Results}

CLINICAL SYMPTOMS AND LABORATORY DATA The initial symptom of neuropathy was weakness of the limbs in 11 patients and a burning sensation in the feet in six patients (table 1). Progression occurred over intervals ranging 
from 3 days to 8 years. In nine patients, weakness progressed to loss of ambulation within 1

A
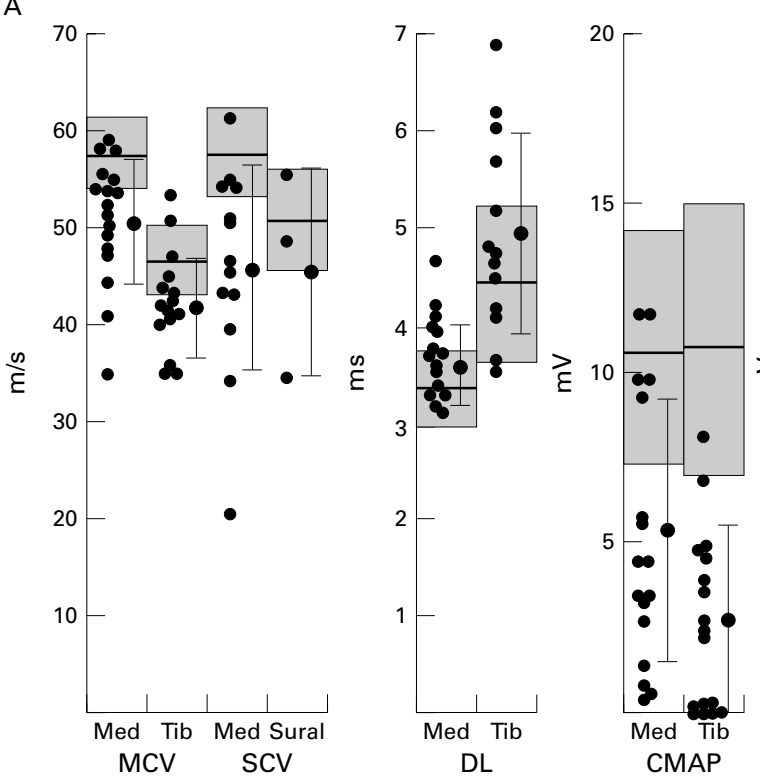

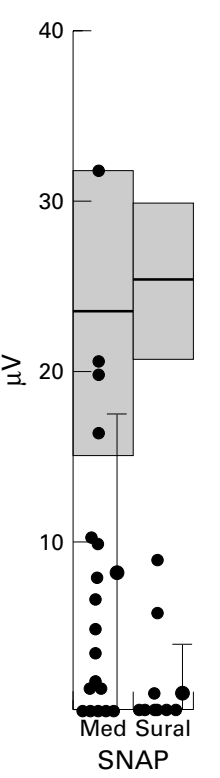

B

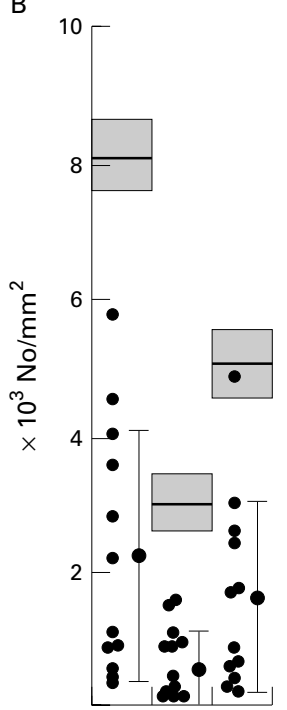

Total Large Sural

MF density

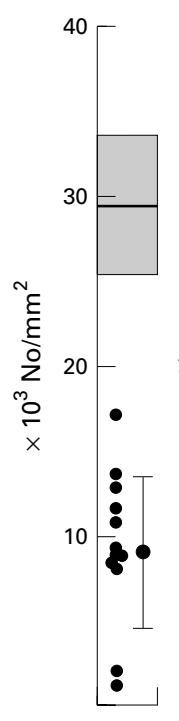

UMF

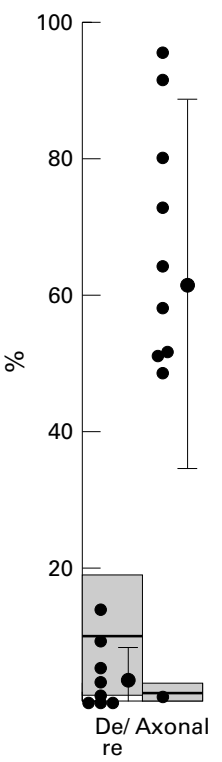

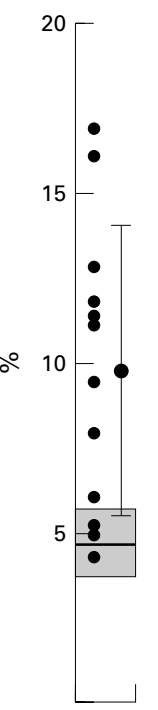

Subperineurial oedema
Figure 1 (A) Electrophysiological findings for the median, tibial, and sural nerves. CMAPs and SNAPs were decreased most markedly in the lower limbs. CMAPs were evoked from the abductor pollicis brevis in all patients, but they could not be obtained from the abductor hallucis in two patients. SNAPs were not evoked in four patients on the median nerve or in 13 patients on the sural nerve. MCV was slowed and DL was mildly prolonged in half of the patients, whereas the SCV was moderately to markedly slowed in most patients. (B) Pathology of the sural nerves. Densities of both large and small myelinated fibres were significantly reduced in most of the cases. Unmyelinated fibre density was also markedly reduced. Axonal degeneration was the most prominent feature, and segmental demyelination and remyelination were rare. Subperineurial oedema was common. Grey columns represent mean (SD) values for control subjects. The bold line across the column is the mean value for controls. Mean (SD) values for patients in series are indicated with bold lines alongside the points plotted. Control values for electrophysiological findings were obtained in 191 normal volunteers (mean age (SD), 48.7 (16.5); men:women, 97:94) for the median nerve, 121 (mean age (SD), 49.9 (15.0); men:women, 64:57) for the tibial nerve, and 133 (mean age (SD), 50.6 (15.6); men : women, 74:59) for the sural nerve. Mean (SD) values for normal control subjects were 57.8 (3.7) $\mathrm{m} / \mathrm{s}, 3.4$ (0.4) $\mathrm{ms}$, and 10.7 (3.5) $\mathrm{mV}$ for MCV,DL, and CMAPs of the median nerve, 46.9 (3.5) $\mathrm{m} / \mathrm{s}, 4.5$ (0.8) $\mathrm{ms}$, and 10.9 (3.8) $\mathrm{m} / \mathrm{s}$ for the tibial nerve; 57.8 (4.7) $\mathrm{m} / \mathrm{s}$ and 23.5 (8.4) $\mu \mathrm{V}$ for $S C V$ and SNAPs of the median nerve, $51.0(5.1) \mathrm{m} / \mathrm{s}$ and 11.5

(4.7) $\mu V$ for the sural nerve. Control values for pathology of the sural nerves were based on previously published reports. ${ }^{21}{ }^{22} M C V=$ motor nerve conduction velocity; $S C V=$ sensory nerve conduction velocity; $D L=$ distal latency; $C M A P=$ compound muscle action potential;

$S N A P=$ sensory nerve action potential; Med=median nerve; Tib=tibial nerve; Sural=sural nerve; $M F=$ myelinated fibre; $U M F=$ unmyelinated fibre; De/re=segmental demyelination and remyelination; Axonal=axonal degeneration. month; some of these patients initially were thought to have Guillain-Barré syndrome, as neuropathy was motor dominant and progression was rapid.

All patients manifested symmetric polyneuropathy with more marked involvement of the lower than the upper limbs. Eleven patients showed muscle atrophy relatively early in the clinical course. Fifteen patients were unable to walk by the time of referral to the hospital. Sensory involvement was distally accentuated in the limbs; it had progressed to include the trunk in five patients. Superficial dominant sensory disturbance was seen in two patients, and deep sensory dominant in four; sensory deficits involved all modalities in 11. A burning sensation or numbness was noted by all patients to varying degrees. Relative degrees of motor and sensory impairment were variable; a motor dominant pattern was seen in 14 patients, and a sensory dominant or purely sensory pattern in three. Cranial nerve involvement such as bilateral facial nerve palsy, hoarseness, or lateral gaze palsy were seen in four patients.

Seven patients had obvious autonomic manifestations. A flaccid bladder was noted in four patients, and urethral catheterisation was required in two. Four patients had severe constipation accompanied by intestinal gas accumulation on abdominal radiographs. Two patients showed severe gas retention that mimicked ileus. One patient had overt signs of orthostatic hypotension with brief attacks of syncope. Cardiac arrhythmias such as bigeminy and atrioventricular block were seen in two patients. None of the patients manifested upper motor neuron signs suggesting cord pathology.

As for other symptoms associated with thiamine deficiency, four patients manifested Wernicke-Korsakoff syndrome, and 10 manifested signs of heart failure such as cardiomegaly on chest radiographs or pitting oedema of the legs. Myalgia in muscles of the limbs was present in four patients.

Concentrations of vitamin B2, B6, B12, folate, and vitamin $\mathrm{E}$ were slightly below the normal range in two, three, two, two, and no patients, respectively. Examination of CSF showed no abnormalities in protein or cell content.

Nerve conduction studies showed markedly decreased amplitude of compound muscle action potentials (CMAPs) and sensory nerve action potentials (SNAPs), most evident in the lower limbs (fig $1 \mathrm{~A}$ ). The CMAPs were evoked from the abductor pollicis brevis in all patients, but they could not be obtained from the abductor hallucis in two patients. No SNAPs were evoked in four patients from the median nerve or in 13 patients from the sural nerve. Motor nerve conduction velocity (MCV) and sensory nerve conduction velocity (SCV) were mildly slowed, and distal latency (DL) was mildly prolonged in some patients. Presence of oedema in the limbs, which subsided in a few days of thiamine administration, did not substantially alter the results of nerve conduction studies. Electromyography was performed 


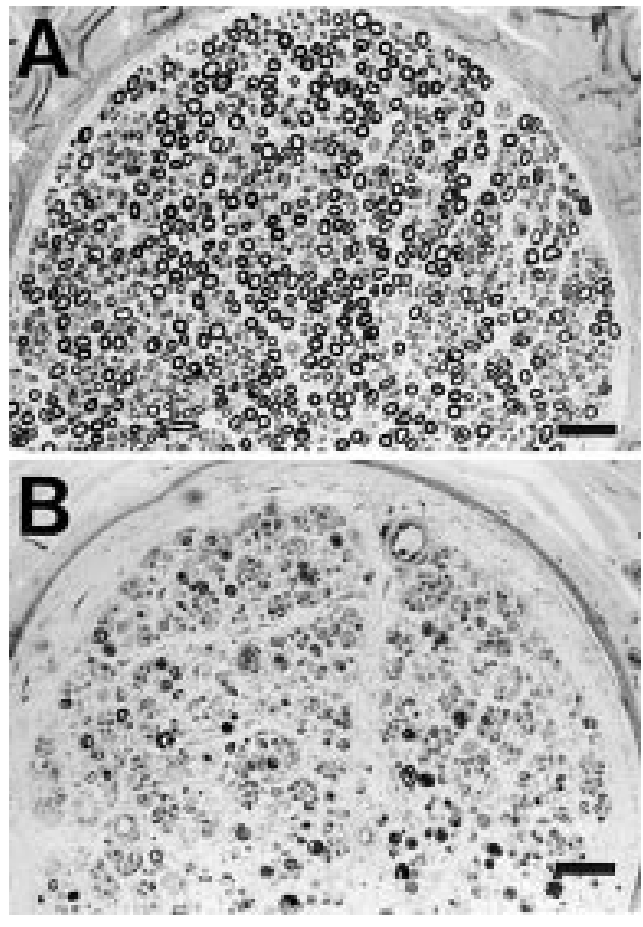

Figure 2 Transverse sections of sural nerve in $(A)$ a control and (B) postgastrectomy patient 2. Note myelin ovoids and significant reduction of the density of myelinated fibres. Large myelinated fibres are more preferably reduced in comparison with small myelinated fibres. Endoneurial oedema with enlargement of subperineurial space is present. The control specimen was obtained from a necropsied patient without neurological diseases. Scale bar $=50 \mu \mathrm{m}$.

in 12 patients. Neurogenic change, especially in the muscles of the lower limbs, was recorded in all of these patients.

Myelinated fibre density in sural nerve biopsy specimens was 356 to 5794 fibres $/ \mathrm{mm}^{2}$ representing varying degrees of reduction (fig 1 $\mathrm{B}$ and 2). Both large and small myelinated fibres were reduced. Unmyelinated fibre density was also decreased (998 to 16956 fibres $/ \mathrm{mm}^{2}$ ). In teased fibre studies, the frequency of fibres with axonal degeneration ranged from $1 \%$ to $96 \%$, while segmental demyelination and remyelination were rare. Subperineurial oedema was present in most specimens. In specimens from patients 6,15 , and 17 , whose biopsy was performed 2 to 3 weeks after initiation of thiamine administration, showed no subperineurial oedema. Significant correlation was seen between myelinated fibre density of sural nerve and modified Rankin score $(p<0.05$, Spearmen's rank correlation).

GASTRECTOMY AND RELATED BACKGROUND

Gastrectomy had been performed 2 months to 39 years before onset of neuropathy (table 2). Methods of reconstruction for gastrectomy were variable including Roux-en-Y, jejunal pouch interposition, Billroth I method, and the Billroth II method. Most patients took particular care of their dietary balance after surgery, but four $(6,9,11$, and 14) showed a mild dietary imbalance including mild hypoproteinaemia. Three patients $(1,2$, and 13$)$ with cancer received chemotherapy with either deoxifluridine or 5-fluorouracil.

\section{TREATMENT AND OUTCOME}

All patients were treated with thiamine. Initially a $100 \mathrm{mg}$ daily intravenous dose of fursultiamine, a disulfide derivative of thiamine, was given for at least 3 days. A $75 \mathrm{mg}$ daily oral dose of fursultiamine was administered subsequently. All patients maintained their blood thiamine concentration above 35 $\mathrm{ng} / \mathrm{ml}$ (the mean for normal control subjects) by oral administration. Cardiomegaly, oedema of the legs, and arrhythmias improved dramatically within a few days after starting thiamine administration. Paresis of the bladder and intestine improved within a few weeks. Improvement of muscle strength was evident in a week. Whereas 15 patients were unable to walk at the time of admission, substantial recovery of functional status occurred; 60 and $80 \%$ of non-ambulatory patients were able to walk within 3 and 6 months of thiamine administration, respectively. Modified Rankin score (mean (SD)) in the initial phase was 3.7 (1.0), improving to $2.2(0.9)$ at 3 months and to 1.9 (0.9) at 6 months. Recovery of sensation was less dramatic than motor recovery; burning sensations noted by all patients in the early phase remained in 16 patients at 6 months and in 14 at 2 years. Wernicke's encephalopathy improved substantially, but Korsakoff's psychosis persisted in one patient at 2 years.

Table 2 Details of gastrectomy and related background

\begin{tabular}{|c|c|c|c|c|c|}
\hline \multirow[b]{2}{*}{ Patient } & \multicolumn{3}{|c|}{ GI tract operation } & \multirow[b]{2}{*}{ GI tract lesion } & \multirow{2}{*}{$\begin{array}{l}\text { Interval } \\
\text { ope-onset (y) }\end{array}$} \\
\hline & Gastrectomy & Reconstruction of gastrectomy & Others & & \\
\hline 1 & Total & Jejunal pouch interposition & & Gastric cancer & 2.5 \\
\hline 2 & Total & Jejunal pouch interposition & & Gastric cancer & 1 \\
\hline 3 & Subtotal & Billroth I & & Gastric ulcer & 38 \\
\hline 4 & Total & Roux-en-Y & & Gastric cancer & 1.3 \\
\hline 5 & Subtotal & Billroth II & & Duodenal ulcer & 27 \\
\hline 6 & Total & Roux-en-Y & & Gastric cancer & 0.8 \\
\hline 7 & Total & Roux-en-Y & & Gastric lymphoma & 12 \\
\hline 8 & Subtotal & Billroth II & & Gastric cancer & 4 \\
\hline 9 & Total & Roux-en-Y & & Gastric ulcer & 39 \\
\hline 10 & Subtotal & Billroth I & & Gastric cancer & 0.2 \\
\hline 11 & Subtotal & Billroth II & & Gastric ulcer & 8 \\
\hline 12 & Subtotal & Billroth I & & Gastric ulcer & 6 \\
\hline 13 & Subtotal & Oesophagogastrostomy & Oesophagectomy & Gastro-oesophageal cancer & 10 \\
\hline 14 & Total & Jejunal pouch interposition & & Gastric cancer & 6 \\
\hline 15 & Subtotal & Billroth I & & Gastric ulcer & 20 \\
\hline 16 & Total & Roux-en-Y & & Gastric cancer & 1 \\
\hline 17 & Subtotal & Billroth II & & Gastric ulcer & 30 \\
\hline
\end{tabular}




\section{Discussion}

All patients in this study showed definite thiamine deficiency evidenced by total thiamine concentration in the whole blood and activity of transketolase in erythrocytes. The most widely accepted evaluation of thiamine status has been functional determination of activity of erythrocyte transketolase, a thiamine dependent enzyme. ${ }^{26}$ However, with the introduction of HPLC in the $1980 \mathrm{~s},{ }^{27}{ }^{28}$ direct thiamine evaluation has been adopted widely because of its high sensitivity and reliability. For diagnosis of thiamine deficiency, total thiamine concentration in whole blood was shown to be essentially as reliable as erythrocyte transketolase activity. ${ }^{29}$ Whereas stores of various nutrients including other $\mathrm{B}$ vitamins and vitamin $\mathrm{E}$ were preserved in most patients, two to three patients showed a concentration slightly below the normal range for various individual B vitamins. Deficiencies of nicotinic acid, $^{30}$ vitamin $\mathrm{B} 2{ }^{31}$ vitamin $\mathrm{B} 6,{ }^{32}$ vitamin $\mathrm{B} 12,{ }^{33}$ and folate ${ }^{34}$ therefore might have influenced the clinical features; however, characteristic symptoms associated with these individual vitamin deficiencies were not present. These clinical pictures include anorexia, diarrhoea, erythematous and hyperkeratotic dermatitis, and mental changes in pellagra (nicotinic acid deficiency); cheilosis, glossitis, keratoconjunctivitis, and dermatitis in vitamin B2 deficiency; and myelopathy in vitamin B12 and folate deficiency. Thus, accompanying mild vitamin deficiencies in some patients were not major causal factors of neuropathy in our patients with thiamine deficiency.

Clinical features of motor-sensory polyneuropathy with wide variation in our series were in agreement with previous descriptions of beriberi..$^{35}$ Major electrophysiological and histopathological findings indicated an axonal neuropathy predominantly involving the lower limbs, also in agreement with previous reports of beriberi. ${ }^{36-38}$ Segmental pathology was strikingly rare in sural nerve biopsy findings, whereas slowing of SCVs and MCVs were seen in some patients when a nerve action potential could be elicited. Such slowing in nerve conduction had been noted in cases of neuropathy resulting from beriberi ${ }^{36}$ and was consistent with findings of polyneuropathy after gastrectomy. ${ }^{39}$ The presence of subperineurial oedema in most patients was also consistent with previous descriptions of beriberi neuropathy. ${ }^{38} 40$

Remarkable functional improvement with thiamine supplementation supported our impression that thiamine deficiency was the major pathogenetic factor in our series. These clinical and biochemical findings indicate that the major factor contributing to the pathogenesis of these postgastrectomy polyneuropathies is thiamine deficiency. There was, however, a considerable discrepancy between the recovery of motor and sensory impairment. Improvement of motor function could be, in part, attributable to some metabolic dysfunction rather than axonal pathology. Further detailed study is needed to clarify this issue.
A history of gastrectomy was a principal feature of our patients with neuropathy. Wernicke's encephalopathy has occasionally been reported in association with operations performed to treat morbid obesity. ${ }^{78}$ Neuropathy can also occur in some patients after gastric restriction surgery for morbid obesity. ${ }^{68}$ Thiamine deficiency may occur in patients who undergo operations for morbid obesity, especially those prone to vomiting. ${ }^{41}$ The major procedures performed to treat morbid obesity were a Roux-en-Y to create a bypass or gastroplasty performed to produce stenosis of the gastrointestinal tract. Patients undergoing such surgery show extensive weight loss, sometimes with protracted nausea and vomiting as well as severe malnutrition. We included no patients with gastric surgery to treat morbid obesity; our patients underwent total or subtotal gastrectomy for neoplasm or ulcer. Our patients, then, differed importantly from those who underwent surgery for morbid obesity; in them, gastrointestinal reconstruction aimed to facilitate adequate oral intake. Unlike patients after surgery for morbid obesity, only one of our patients had vomiting and extensive weight loss (patient 6), and most patients were careful to consume a balanced diet after the operation. Some of our patients had carcinomas, but tumours did not show recurrence or metastasis at the time neuropathic symptoms appeared.

Thiamine is absorbed by the mucosa of the entire intestine, with the highest rate of absorption occurring in the duodenum. ${ }^{42-44}$ Occurrence of thiamine deficiency therefore is puzzling, as a large extent of intestine, presumably able to absorb thiamine, was left intact. However, recent reports concerning Wernicke's encephalopathy ${ }^{9-12}$ suggest that thiamine deficiency can occur in some, though not all, patients who undergo gastrectomy for cancer. Electrophysiological evidence of neuropathy was noted in some patients with Wernicke's encephalopathy postgastrectomy. ${ }^{912}$ Markkanen ${ }^{45}$ reported that the activity of erythrocyte transketolase decreased in 31\% of patients with operations involving the upper gastrointestinal tract, including partial gastrectomy. These findings suggest that the relative abilities of different intestinal sites to absorb thiamine may vary among subjects. Furthermore, as only a few of the many patients who undergo gastrectomy develop neuropathy, individual factors including genetic variation may influence.

Most patients in our series did not manifest neuropathic symptoms in the early period after gastrectomy, even though many of them had an acute onset of symptoms. A patient with a history of gastrectomy could have a subclinical deficiency of thiamine despite appropriate dietary intake, and subsequently experience an increased thiamine requirement as with fever, anorexia, heavy labour, pregnancy, or other conditions. Symptoms of thiamine deficiency might then be precipitated. Worsening of subclinical thiamine deficiency associated with aging $^{46} 47$ also could account for a delayed appearance of neuropathic symptoms after gastrectomy in some patients. Medication with 
fluoropyrimidines was considered to have influenced in the development of thiamine deficiency in patients 1,2 , and 13 because these have been reported to increase the cellular metabolism of thiamine. ${ }^{48}$

As functional recovery from polyneuropathy was relatively good after treatment, we think that thiamine should be assayed and administered early in patients with motor-sensory polyneuropathy and a history of gastrointestinal surgery. Prophylactic supplementation of thiamine after gastrectomy also may be advisable.

We thank Drs Y Takeuchi, (Department of Neurology, Ekisaika Hospital, Aichi); H Tanaka, (Department of Neurology, Kyoritsu General Hospital, Aichi); K Mano, (Department of Neurology, Daiichi Red-Cross Hospital, Aichi); K Imamura, (Department of Neurology, Okazaki Municipal Hospital, Aichi); J Ochiai, (Department of Neurology, Nakatsugawa
Municipal Hospital, Gifu); and Teruo Shirabe, (Department of Neuropathology, Kawasaki Medical Umiversity, Okayama); for the provision of clinical data. This study was supported by the grants from the Ministry of Health and Welfare of Japan.

1 Reuler JB, Girard DE, Cooney TG. Wernicke's encephalopathy. $N$ Engl F Med 1985;312:1035-9.

2 Baeltz B. Ueber das Verhältniss der multiplen peripherischen Neuritis zur Beriberi (Panneuritis endemica). Z Klin Med 1882;4:616-7.

3 Funk C. On the chemical nature of the substance which cures polyneuritis in birds induced by a diet of polished cures polyneuritis in birds induced by
rice. F Physiol (Lond) 1911;43:395-400.

4 Darnton-Hill I, Truswell S. Thiamine status of a sample of homeless clinic attenders in Sydney. Med f Aust 1990;152: $5-9$

5 Zac J 3rd, Burns D, Lingenfelser T, et al. Dry beriberi: unusual complication of prolonged parenteral nutrition. F Parent Enteral Nut 1991;15:200-1.

6 Feit H, Glasberg M, Ireton C, et al. Peripheral neuropathy and starvation after gastric partitioning for morbid obesity. Ann Intern Med 1982;96:453-5.

7 Oczkowski WJ, Kertesz A. Wernicke's encephalopathy after gastroplasty for morbid obesity. Neurology 1985;35:99-101.

8 Abarbanel JM, Berginer VM, Osimani A, et al. Neurologic complications after gastric restriction surgery for morbid obesity. Neurology 1987;37:196-200.

9 Okino S, Sakajiri K, Fukushima K, et al. A case of Wernicke-Korsakoff syndrome caused by gastrojejunostomy: specific findings of MRI and SPECT Clin Neurol (fapan) 1993;33:530-4

10 Batori M, Ciulli A, Lazzaro M, et al. Wernicke's encephalopathy post subtotal extended gastrectomy. Eur Rev Med

11 Arai M, Nara K, Awazu N. Wernicke's encephalopathy developed several years after total gastrectomy. Report of 2 cases. Clin Neurol (fapan) 1997;37:1027-9.

12 Shimomura T, Mori E, Hirano N, et al. Development of Wernicke-Korsakoff syndrome after long intervals following gastrectomy. Arch Neurol 1998;55:1242-5.

13 Benerji NK, Hurwitz LJ. Nervous system manifestations after gastric surgery. Acta Neurol Scand 1971;47:485-513.

14 Hoffman PM, Brody JA. Neurological disorders in patients following surgery for peptic ulcer. Neurology 1972;22:450.

15 Herve C, Beyne P, Lettéron P, et al. Comparison of erythrocyte transketolase activity with thiamine and thiamine phosphate ester levels in chronic alcoholic patients. Clin Chim Acta 1995;234:91-100.

16 Kimura J. Principles of nerve conduction studies. In: Kimura J, ed. Electrodiagnosis in disease of nerve and muscle:
principles and practice. 2nd ed. Philadelphia: FA Davis, principles and

17 Kimura J. Assessment of individual nerves. In: Kimura J, ed. Electrodiagnosis in disease of nerve and muscle: principles and practice. 2nd ed. Philadelphia: FA Davis, 1989:103-38.

18 Sobue G, Yasuda T, Mitsuma T, et al. Expression of nerve growth factor receptor in human peripheral neuropathies. Ann Neurol 1988;24:64-72.

19 Hattori N, Ichimura M, Nagamatsu M, et al. Clinicopathological features of Churg-Strauss syndrome-associated neuropathy. Brain 1999;122:427-39.
20 Misu K, Hattori N, Nagamatsu M, et al. Late-onset familial amyloid polyneuropathy type I (transthyretin Met 30associated familial amyloid polyneuropathy) unrelated to endemic focus in Japan; clinicopathological and genetic features. Brain 1999;122:1951-62.

21 Sobue G, Hashizume Y, Mukai E, et al. X linked recessive bulbospinal neuronopathy, a clinicopathological study. Brain 1989;112:209-32.

22 Nagamatsu M, Terao S, Misu K, et al. Axonal and perikaryal involvement in chronic inflammatory demyelinating polyneuropathy. I Neurol Neurosurg Psychiatry 1999;66: $27-33$

23 Sobue G, Li M, Terao S, et al. Axonal pathology in Japanese Guillain-Barré syndrome; a study of 15 autopsied cases. Neurology 1997;48:1694-700.

24 Dyck PJ, Giannini C, Lais A. Pathologic alterations of nerves. In: Dyck PJ, Thomas PK, Griffin JW, et al, ed. Peripheral neuropathy. 3rd ed. Philadelphia: WB Saunders, 1993:514-95.

25 van Swieten JC, Koudstaal PJ, Visser MC, et al. Interobserver agreement for the assessment of handicap in stroke patients. Stroke 1988;19:604-7.

26 Dreyfus PM. Clinical application of blood transketolase determinations. N Engl f Med 1962;267:596-8.

27 Kimura M, Fujita T, Itokawa Y. Liquid chromatographic determination of the total thiamine content of blood. Clin Chem 1982;28:29-31.

28 Froridi A, Pupita M, Palmerini CA, et al. Thiamine pyrophosphate determination in whole blood and erythrocyts by high performance liquid chromatography. Int 7 Vitam Nutr Res 1984;54:165-71.

29 Kuriyama $\mathrm{M}$, Yokomine $\mathrm{R}$, Arima $\mathrm{H}$, et al. Blood vitamin $\mathrm{B} 1$, transketolase and thiamine pyrophosphate (TPP) effect in beriberi patients, with studies employing discriminant analysis. Clin Chim Acta 1980;108:159-68.

30 Spies TD, Chinn AB, McLester JB. Severe endemic pellagra: a clinical study of fifty cases with special emphasis on therapy. $\mathcal{F} A M A$ 1937;108:853-7.

31 Cotran RS, Kumar V, Robbins SL. Nutritional disease. In: Robbins pathologic basis of disease. 4th ed. Philadelphia: WB Saunders, 1989:435-67.

32 Raskin NH, Fishman RA. Pyridoxine-deficiency neuropathy due to hydralazine. $N$ Engl f Med 1965;273:1182-5.

33 McCombe PA, McLeod JG. The peripheral neuropathy of vitamin B12 deficiency. $\mathcal{F}$ Neurol Sci 1984;66:117-26.

34 Botez MI, Peyronnard JM, Bachevalier J, et al. Polyneuropathy and folate deficiency. Arch Neurol 1978;35:581-4.

35 Pekelharing CA, Wrinkler C. Mittheilung über die Beriberi. Dtsch Med Wochenschr 1887;13:845-8.

36 Takahashi K. Thiamine deficiency neuropathy, a reappraisal. Int f Neurol 1981;15:245-53.

37 Takahashi K, Nakamura H. Axonal degeneration in beriberi neuropathy. Arch Neurol 1976;33:836-41.

38 Ohnishi A, Tsuji S, Igisu H, et al. Beriberi neuropathy. $\mathcal{f}$ Neurol Sci 1980;45:177-90.

39 Behse F, Buchthal F. Alcoholic neuropathy: clinical, electrophysiological, and biopsy findings. Ann Neurol 1977;2:95110.

40 Watanabe S, Ohnishi A. Subperineurial space of the sural nerve in various peripheral nerve diseases. Acta Neuropathol 1979;46:227-30.

41 MacLean LD, Rhode BM, Shizgal HM. Nutrition following gastric operations for morbid obesity. Ann Surg 1983;198: $347-55$.

42 Rindi G, Ferrari G. Thiamine transport by human intestine in vitro. Experimentia 1977;33:211-3.

43 Hoyumpa AM Jr. Alcohol and thiamine metabolism: alcoholism. Clin Exp Res 1983;7:11-4.

44 Laforenza U, Patrini C, Albisi C, et al. Thiamine uptake in human intestinal biopsy specimens, including observations from a patient with acute thiamine deficiency. Am f Clin Nutr 1997;66:320-6.

45 Markkanen T. Metabolic disturbance after gastrooesophageal resection. Int $\mathcal{F}$ Vitam Nutr Res 1973;43:54954.

46 Vir SC, Love AHG. Nutritional status of institutionalized and non-institutionalized aged in Belfast, Northern Ireland. Am 7 Clin Nutr 1979;32:1934-47.

47 O'Keeffe ST, Tormey WP, Glasgow R, et al. Thiamine deficiency in hospitalized elderly patients. Gerontology 1994;40: $18-24$

48 Heier MS, Dornish JM. Effect of the fluoropyrimidines 5 -fluorouracil and deoxifluridine on cellular uptake of thiamine. Anticancer Res 1989;9:1073-8. 